\title{
Flavia Freidenberg y Gabriela del Valle Pérez (Eds.), Cuando hacer política te cuesta la vida. Estrategias contra la violencia política hacia las mujeres en América Latina, México, UNAM/Instituto Electoral de la Ciudad de México, 2017, 378 pp.
}

Reseña por Mariana Caminotti*

Perfiles Latinoamericanos, 27(54) | 2019

DOI: $10.18504 / \mathrm{pl} 2754-017-2019$

\section{$\square$}

acoso y la violencia que las mujeres experimentan en la vida política por el hecho de ser mujeres es uno de los principales obstáculos para su participación y proyección política. En los últimos años, las manifestaciones de violencia política en razón del género se agravaron, especialmente en aquellos países donde la aprobación de reformas electorales inclusivas posibilitó que las mujeres accedan de manera significativa a los espacios de representación antes monopolizados por hombres. La política, como arena de disputa y de ejercicio del poder, siempre ha sido un terreno hostil para las mujeres, pero al ampliarse sus candidaturas y sus niveles de representación descriptiva, las resistencias se han hecho más visibles y, en muchos casos, más cruentas.

Las expresiones de acoso y de violencia política han despertado preocupación entre activistas, grupos de parlamentarias, organismos internacionales y gobiernos, y están dando paso a iniciativas que apuntan a lograr reformas en la legislación y en las políticas públicas. El propósito del libro editado por Freidenberg y Del Valle Pérez es precisamente aportar al conocimiento y a la visibilización del acoso y la violencia política en razón del género, entendida esta última como uno de los problemas más acuciantes que enfrentan las mujeres que incursionan en política en América Latina. Estos propósitos están plenamente logrados gracias a una cuidadosa selección de capítulos organizados en secciones que aportan claridad y coherencia a la obra. Se trata de un libro fundamental

\footnotetext{
* Doctora en Ciencia Política por la Universidad Nacional de San Martín (unsam) (Argentina). Investigadora del Consejo Nacional de Investigaciones Científicas y Técnicas de la Argentina (CONICET) en la Escuela de Política y Gobierno de la unsam y Profesora Adjunta regular en la misma universidad. Cocoordinadora de la Red de Politólogas | mcaminotti.unsam@gmail.com
} 
para la comprensión de una problemática crucial en la región, pues devela una serie de prácticas sutiles o evidentes, directas o indirectas, que socavan el pleno goce y ejercicio de los derechos políticos y electorales de las mujeres.

El volumen analiza la problemática de la violencia política de género desde una perspectiva multidisciplinar, reuniendo trabajos de académicas, funcionarias/os electorales y activistas, lo cual aporta una pluralidad de perspectivas y tiende puentes entre el conocimiento y la praxis política transformadora, cuestionando la desigualdad y la opresión que todavía experimentan las mujeres de diferente condición en la región. El libro - fruto del esfuerzo colectivo de veintidós investigadoras/es de Estados Unidos y América Latina — contribuye a llenar una laguna en el conocimiento empírico y aporta interesantes elementos para la conceptualización y medición de la violencia política en razón de género. El volumen recoge trabajos presentados en el Seminario Internacional "Violencia política contra las mujeres en América Latina: diagnósticos, diálogos y estrategias", organizado por el Instituto de Investigaciones Jurídicas de la UNAM, el TEPJF y la Fepade en la Ciudad de México en noviembre de 2015, junto con artículos de expertos y expertas.

El capítulo introductorio presenta un estado de la situación de la violencia política contra las mujeres en América Latina, enfatizando en la naturaleza del fenómeno, en su conceptualización y en sus implicancias. Se revisan los debates y las propuestas existentes para hacer frente al problema, brindando un excelente punto de partida. La primera sección agrupa tres capítulos que contribuyen al debate teórico y brindan herramientas conceptuales para lidiar con la complejidad de las definiciones. Estas contribuciones aportan a la diferenciación de los conceptos de violencia de género, violencia política, sexismo y violencia política en razón del género, evidenciando que las formas de enmarcar y conceptualizar el problema no son neutras.

Pese a que la discriminación y la marginalización de las mujeres ha sido un rasgo estructural de la política en la región, el concepto de violencia política de género es relativamente nuevo. Precisamente, una de las virtudes principales del libro es plantear las ambigüedades que deberían resolverse para ganar en precisión y contribuir a establecer indicadores que permitan tipificar las formas de violencia y avanzar en el diseño de acciones para su medición, prevención y sanción. Con todo, los capítulos dejan entrever que el debate aún no está saldado y que hay distintas aproximaciones en distintos contextos que tienen profundas consecuencias para las soluciones de política planteadas por actores/as nacionales, transnacionales e internacionales. Las definiciones importan, ya que condicionan la forma en que los Estados movilizan recursos e instituciones para enfrentarlos (véase el capítulo de Jennifer M. Piscopo). Los buenos conceptos contribuyen a recolectar buenos datos, a llevar a cabo análisis útiles 
y desarrollar soluciones para atender y erradicar el problema (véase el capítulo de Mona Lena Krook).

La segunda sección consta de cuatro capítulos que analizan los marcos normativos existentes en relación con el acoso y la violencia política contra las mujeres en América Latina. En conjunto, estos trabajos brindan una caracterización de la situación actual desde una perspectiva comparada y, al mismo tiempo, proponen criterios para la elaboración de normas que permitan lidiar con el problema, tanto desde el punto de vista de las leyes específicas como de reformas más amplias. De esta manera, la sección es de particular utilidad para activistas y hacedores/as de política.

La tercera parte de la obra se destina al análisis de las estrategias institucionales frente al acoso y la violencia política contra las mujeres en México. Los trabajos reunidos en esta sección proporcionan abundante evidencia sobre las formas que asume la violencia política contra las mujeres en el país, describen iniciativas de cambio en la legislación y analizan el rol clave que han desempeñado la justicia electoral y los organismos electorales en los últimos ańos. A su vez, se proponen acciones para atender, sancionar y eliminar la violencia política de género desde el Estado y los partidos políticos. Es destacada la discusión sobre la violencia política contra las mujeres indígenas, una problemática que requiere de un debate específico desde las dimensiones cultural y jurídica. Sin embargo, en este punto el libro no llega a resolver los problemas de la comparación y se echan en falta capítulos que aborden la interseccionalidad en casos diferentes al mexicano, lo que hubiese contribuido a la comprensión del fenómeno de una manera más certera.

La cuarta sección del libro analiza casos de acoso y violencia política contra las mujeres en ámbitos subnacionales de Bolivia, Perú y México. Si bien los casos de Oaxaca o Chiapas en México son muy significativos para comprender el peso específico que la violencia política tiene en el nivel subnacional, se podrían haber incorporado más experiencias que permitan entender mejor este obstáculo y encontrar rasgos sistemáticos. En suma, en contraposición con cierta visión convencional de lo local como un espacio más propicio para la participación política de las mujeres, este libro sugiere que puede ser una arena hostil, aunque la obra se hubiese beneficiado de una mayor cantidad de análisis cualitativos acerca del modo específico en que se manifiesta la violencia institucional y partidista en el ámbito municipal en distintos contextos.

Además de brindar una caracterización de los casos y manifestaciones de violencia y de su relación con los contextos, los trabajos reunidos discuten el papel de las organizaciones sociales de mujeres, organismos estatales y agencias internacionales para medir, dar a conocer y enfrentar el problema. Además, los capítulos permiten extraer lecciones para la acción y la incidencia política en 
materia de protección y ampliación de los derechos políticos de las mujeres, y este es un valor adicional de la obra. Las conclusiones sistematizan los debates y hallazgos, y sugieren nuevas líneas de reflexión y de investigación a futuro. Pero, sobre todo, el libro en su conjunto abona a la construcción de una agenda que aúna la generación de conocimiento sistemático con el diseño de políticas basadas en evidencia para la erradicación de la violencia política contra las mujeres en América Latina. 